Elsevier Editorial System(tm) for Placenta Manuscript Draft

Manuscript Number: PL-17-00065R1

Title: Glycosylation and Immunocytochemistry of Binucleate cells in Pronghorn(Antilocapra americana, Antilocapridae) show features of both Giraffidae and Bovidae

Article Type: Full Length Article

Keywords: Pronghorn; lectins; placenta; binucleate cells; Giraffidae; Bovidae

Corresponding Author: Dr. Carolyn Jane Jones, PhD, DMedSc

Corresponding Author's Institution: University of Manchester

First Author: Carolyn Jane Jones, PhD, DMedSc

Order of Authors: Carolyn Jane Jones, PhD, DMedSc; William J Silvia, PhD; Hugo Hamilton; Thomas W Geary; Abigail L Zezeski; Peter F Wooding, PhD

Abstract: Although the pronghorn (Antilocapra americana) resembles an antelope, its nearest relatives are the giraffe and okapi. In this study we have examined the placentae of 6 pronghorns using lectin- and immunocytochemistry to identify giraffid and bovid features. Binucleate cells (BNC) of the placenta exhibited features intermediate between those of the giraffe and bovine; Dolichos biflorus agglutinin binding - strong in the bovine BNC and absent in the giraffe - was evident in only a subpopulation of BNC while binding to blood vessels, as in the giraffe. Binding of Phytolacca americana agglutinin resembled that of the giraffe and okapi whereas many other glycans were found in all four clades. PAG antigens were similar to bovine and okapi but not giraffe. In summary, although the pronghorn outwardly resembles an antelope, placental BNC show giraffid features. Although each clade has its own individual characteristics, there are far more similarities than differences between them, emphasizing the common ancestry of all four clades. 


\section{Glycosylation and Immunocytochemistry of Binucleate cells in Pronghorn}

(Antilocapra americana, Antilocapridae) Show Features of Both

\section{Giraffidae and Bovidae}

Carolyn J.P. Jones ${ }^{a^{*}}$, W.J. Silvia (deceased) ${ }^{b}$, C.H. Hamilton ${ }^{b}$, T.W. Geary ${ }^{c}$, A.L. Zezeskic , F.B. P. Wooding ${ }^{d}$

aMaternal and Fetal Health Research Centre, Division of Developmental Biology and Medicine, School of Medical Sciences, Faculty of Biology, Medicine and Health, University of Manchester, St Mary's Hospital, Oxford Road, Manchester M13 9WL, U.K.

${ }^{b}$ Department of Animal and Food Sciences, University of Kentucky, Lexington, Kentucky 40546-0215, USA. (Email: chamilto@uky.edu)

'United States Department of Agriculture, Agricultural Research Service, Fort Keogh, Miles City, MT 59301, USA. (Emails: tom.geary@ars.usda.gov, abby.zezeski@ars.usda.gov) ${ }^{\mathrm{d}}$ The Physiological Laboratory, University of Cambridge, Downing Site, Cambridge CB2 3EG, UK (Email: fbpw2@cam.ac.uk)

Author for correspondence: Dr Carolyn Jones, Maternal and Fetal Health Research Centre, St Mary's Hospital 5th floor (Research), Oxford Road, Manchester M13 9WL. UK Email: carolyn.jones@manchester.ac.uk 


\section{Abstract}

Although the pronghorn (Antilocapra americana) resembles an antelope, its nearest relatives are the giraffe and okapi. In this study we have examined the placentae of 6 pronghorns using lectin- and immunocytochemistry to identify giraffid and bovid features. Binucleate cells (BNC) of the placenta exhibited features intermediate between those of the giraffe and bovine; Dolichos biflorus agglutinin binding - strong in the bovine BNC and absent in the giraffe - was evident in only a subpopulation of BNC while binding to blood vessels, as in the giraffe. Binding of Phytolacca americana agglutinin resembled that of the giraffe and okapi whereas many other glycans were found in all four clades. PAG antigens were similar to bovine and okapi but not giraffe. In summary, although the pronghorn outwardly resembles an antelope, placental BNC show giraffid features. Although each clade has its own individual characteristics, there are far more similarities than differences between them, emphasizing the common ancestry of all four clades. 

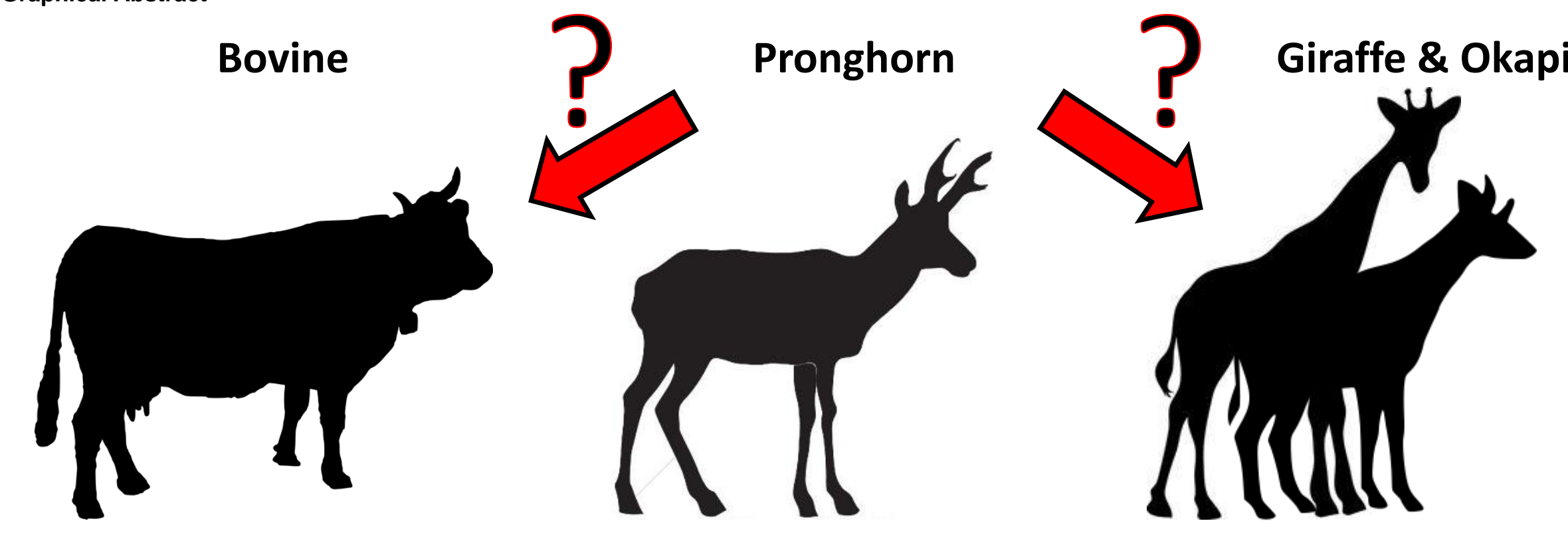

Staining of placenta with Dolichos biflorus agglutinin (DBA)

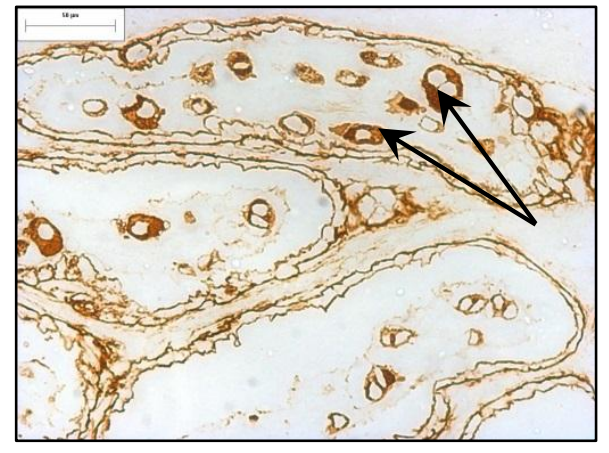

Bovine

Almost all binucleate cells (arrows) stain with DBA. Blood vessels are negative.

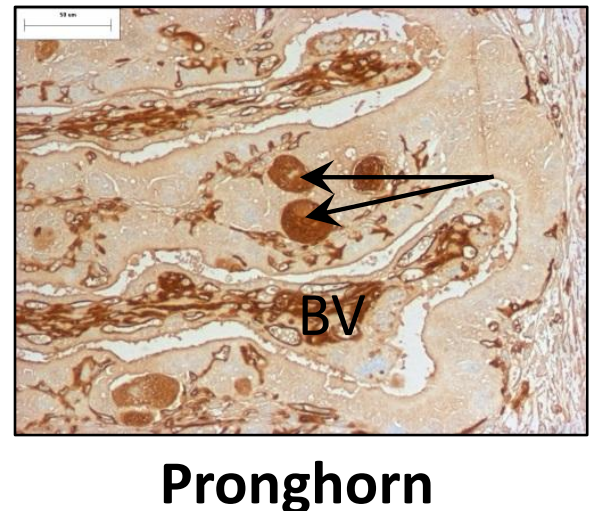

Only a subpopulation of binucleate cells stains with DBA (arrows). Blood vessels (BV) stain.

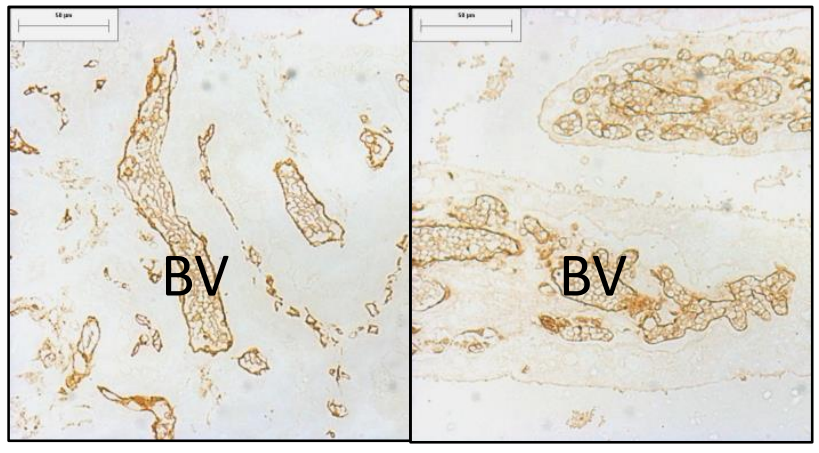

Giraffe

Okapi

No binucleate cells stain with DBA. Blood vessels (BV) are stained. 


\section{Highlights}

- The binucleate cells of the Pronghorn placenta were examined for giraffid features

- DBA binding to BNC showed features of both Giraffidae and Bovidae

- $\quad$ PAA binding to BNC was similar to giraffe and different from the bovine.

- PAG immunocytochemistry was like that of bovine and okapi but not giraffe.

- Pronghorn placenta shows features both of Giraffidae and Bovidae. 


\title{
Glycosylation and Immunocytochemistry of Binucleate cells in Pronghorn (Antilocapra americana, Antilocapridae) Show Features of Both
}

\section{Giraffidae and Bovidae}

\author{
Carolyn J.P. Jones ${ }^{a^{*}}$, W.J. Silvia (deceased) ${ }^{b}$, C.H. Hamilton ${ }^{b}$,T.W. Geary ${ }^{c}$, \\ A.L. Zezeskic ${ }^{\mathrm{C}}$, F.B. P. Wooding ${ }^{\mathrm{d}}$
}

${ }^{a}$ Maternal and Fetal Health Research Centre, Division of Developmental Biology and Medicine, School of Medical Sciences, Faculty of Biology, Medicine and Health, University of Manchester, St Mary's Hospital, Oxford Road, Manchester M13 9WL, U.K. ${ }^{b}$ Department of Animal and Food Sciences, University of Kentucky, Lexington, Kentucky 40546-0215, USA. (Email: chamilto@uky.edu)

'United States Department of Agriculture, Agricultural Research Service, Fort Keogh, Miles City, MT 59301, USA. (Emails: tom.geary@ars.usda.gov, abby.zezeski@ars.usda.gov) ${ }^{\mathrm{d}}$ The Physiological Laboratory, University of Cambridge, Downing Site, Cambridge CB2 3EG, UK (Email: fbpw2@cam.ac.uk)

Author for correspondence: Dr Carolyn Jones, Maternal and Fetal Health Research Centre, St Mary's Hospital 5th floor (Research), Oxford Road, Manchester M13 9WL. UK Email: carolyn.jones@manchester.ac.uk 


\section{Abstract}

Although the pronghorn (Antilocapra americana) resembles an antelope, its nearest relatives are the giraffe and okapi. In this study we have examined the placentae of 6 pronghorns using lectin- and immunocytochemistry to identify giraffid and bovid features. Binucleate cells (BNC) of the placenta exhibited features intermediate between those of the giraffe and bovine; Dolichos biflorus agglutinin binding - strong in the bovine BNC and absent in the giraffe - was evident in only a subpopulation of BNC while binding to blood vessels, as in the giraffe. Binding of Phytolacca americana agglutinin resembled that of the giraffe and okapi whereas many other glycans were found in all four clades. PAG antigens were similar to bovine and okapi but not giraffe. In summary, although the pronghorn outwardly resembles an antelope, placental BNC show giraffid features. Although each clade has its own individual characteristics, there are far more similarities than differences between them, emphasizing the common ancestry of all four clades.

\section{Keywords:}

Pronghorn; lectins; placenta; binucleate cells; Giraffidae; Bovidae 


\section{Introduction}

1 The pronghorn (Antilocapra americana, Antilocapridae) is an artiodactyl mammal

2 indigenous to North America and is often referred to locally as an antelope. However,

3 phylogenetically Antilocapridae occurs in a superfamily, Giraffoidea, with giraffes and

4 okapi (Giraffidae). In the Pleistocene period, there were 12 taxa of the family

5 Antilocapridae but now the pronghorn is the only extant species. It bears characteristic

6 forked horns [1] that are covered in skin as in giraffes, but in the pronghorn this becomes

7 a keratinous sheath which is shed and regrown on an annual basis [2].

8

9 An important feature of the ruminant placenta is the fetal chorionic binucleate cell (BNC)

10 which migrates across the microvillous membrane to fuse with maternal cells, forming

11 fetomaternal trinucleate cells or syncytial masses [3]. These binucleate cells contain

12 heavily glycosylated granules which have been shown to contain placental lactogens

13 which, on migration, pass over to the maternal circulation [4]. Recently, we showed that

14 the placental binucleate cell (BNC) of the giraffe and okapi has a different pattern of

15 glycosylation from other ruminant BNCs that we have studied [5]: greater malayan

16 chevrotain (Tragulidae); fallow deer, red deer, Chinese water deer (Cervidae), domestic

17 goat, springbok, impala, domestic cow and sheep (Bovidae) with little or no expression of

18 terminal aN-acetylgalactosamine bound by Dolichos biflorus and Vicia villosa agglutinins

19 which instead bind to placental blood vessels [6]. We also demonstrated different patterns

20 of protein expression in the BNC [7].

22 It appeared that Giraffidae BNC developed different pathways in their glycan biosynthesis 23 and protein expression following their split from the Bovidae, with further differences 
24 evolving as okapi and giraffe diverged from each other. Because the pronghorn-giraffe clade (or Antilocapridae-Giraffidae clade) diverged from Bovidae [8], it is possible that pronghorn BNC might be different from bovine BNC. We therefore examined placentae from six specimens in order to characterise the glycosylation and protein expression of the binucleate cells and to compare them with those from the giraffe, okapi and bovine.

29

\section{Materials and Methods}

\subsection{Animals.}

All procedures for collection of animals and tissues were approved by the Fort Keogh Institutional Animal Care and Use Committee (IACUC No. 032415-1). The six pronghorn placental samples (Table 1) were collected and fixed within 20 minutes after death as part of a wider investigation of pronghorn biology carried out in eastern Montana. Whole placentomes, consisting of fetal cotyledons in close association via microvillous interdigitation with maternal caruncles that form button-like outgrowths on the surface of the uterus, were placed at $4^{\circ} \mathrm{C}$ in Surgipath I B F fixative (isopropyl alcohol, methanol, barium chloride and <3\% formaldehyde, Leica Biosystems Inc, Buffalo Grove, IL 60089, USA) for 14 days. Central slices of each pronghorn placentome were then cut, put into fresh Surgipath fixative and sent to the UK. The six pronghorn samples had crown rump lengths (from the top of the head to the rump just above the tail) of one of twin fetuses extending from 277 to $318 \mathrm{~cm}$ (approximately 160-190 days old, gestation being 240 days). "Matchstick" samples from the central region of each placentome slice from maternal to fetal edge were embedded in epoxy resin. 


\subsection{Lectin histochemistry.}

51 Sections $0.75 \mu \mathrm{m}$ thick were cut, deresinated in sodium ethoxide, and stained with a panel of 23 biotinylated lectins (see table 2 for details) at $10 \mu \mathrm{g} / \mathrm{ml}$ as previously described [9] except that SNA-1 was used at a concentration of $50 \mu \mathrm{g} / \mathrm{ml}$. Some deresinated sections were treated with Type VI neuraminidase (Sigma, from Clostridium perfringens) in $0.2 \mathrm{M}$ acetate buffer, $\mathrm{pH} 5.5$, with $1 \%(\mathrm{w} / \mathrm{v})$ calcium chloride at $37^{\circ} \mathrm{C}$ for $2 \mathrm{~h}[10]$ to remove terminal sialic acid prior to lectin staining. This revealed glycan residues that were previously masked by the sialic acid. Controls were as previously described [9]. For BSAII staining for amylase-sensitive glycogen [11], the trypsinisation step was omitted and staining was controlled by digestion in $1 \%$ amylase (Sigma, UK) for 20 min at $37^{\circ} \mathrm{C}$ following by washing in running water for 10 mins. Sections were compared with those of

61 giraffe, okapi and bovine (Bos taurus) from our previous study [6] which had been embedded and stained with the same panel of lectins in a similar manner. Subsequently, a series of 8 serial sections was cut from each pronghorn specimen and stained with lectins of particular interest (UEA-1, I-PHA, DBA, VVA, ECA, PAA and WGA) so that specific BNC cells could be tracked to determine glycan characteristics for individual cells. Specific BNC and villi were visualized for the same tissue by overlaying identical

67 fields following staining procedures.

68

\subsection{Immunocytochemistry.}

70 Samples were postfixed overnight in 4\% (para)formaldehyde in PBS with or without $1 \%$ 71 glutaraldehyde before epoxy embedding. Semithin sections were cut, picked up on cover 72 glass squares treated with APES and deresinated in sodium ethoxide. The cover glass 73 squares were then floated section side down on drops of antibody followed by 74 immunogold colloid (goat anti-rabbit G5, Jackson Immunoresearch Labs, USA) then 
75 intensified with silver reagent ( Aurion, Wagenigen, Netherlands). The antibodies used were to Pregnancy Associated Glycoproteins (PAGs) Ovine PAG-1 and Bovine PAG-2

77 [12] used at a dilution of 1:1000, SBU-3 $[13,14]$, bovine Placental Lactogen (bPL) and prolactin (PRL) [7], all at 1:100. Controls with buffer substituted for antibody showed no significant labelling. The two postfixations produced similar results.

80

\section{Results}

82

\subsection{General structure of the placentome}

84 As in all ruminant placentomes, development starts from a flat apposition of trophoblast and uterine epithelium. Mutual growth of the fetal and maternal layers produces placentomes consisting of chorionic villi interdigitating with maternal villi. The fetal digitiform primary villi branch off short, leaf-like secondary villi at right angles to the primary ones while the endometrial villi contain secondary villi to house the secondary fetal villi (Fig 1A, B). The maternal villi are covered with uterine epithelium underneath which are small blood vessels running along the stroma, while the trophoblast covers primary fetal villi that have a similar subepithelial capillary network with a broader and more loosely arranged mesenchymal core through which run large blood vessels.

94 The bases of the fetal villi have more regularly arranged columnar cells than cells on the villus sides, similar to those of the arcade regions at the very tips of the villi which are continuous with the flat intercotyledonary area of the placenta (Fig.1A) on the fetal side,

97 which joins up adjacent cotyledons. 


\subsection{Lectin histochemistry of binucleate cells (BNC)}

101 Lectin histochemistry of BNC is summarised in Table 2. There was little detectable difference in the results between specimens and two (specimens 1 and 6) are presented in the table as typical examples. There was, however, great variability both in the

104 distribution of BNC stained (Figs 1 C,D) and in their staining intensity with the various 105 lectins (Figs 1E-H). BNC in the basal regions tended to be smaller than those in the secondary villi themselves while in the arcade region they were large with rather dispersed granules. LEA (Fig. 1C), ECA with neuraminidase, WGA, and PAA both with or without neuraminidase treatment stained the majority of BNC throughout the placentome. In contrast to this, DBA (Fig. 1D) and VVA, did not stain the BNC in in the basal areas or arcade region though staining of cells in secondary villi was strong. This was also evident to some extent with I-PHA, ECA without neuraminidase (Figs 1E, H) and WFA, where some generally small stained cells were evident in the basal regions but there were more at the tips of the secondary villi. Conversely, the few cells that bound

114 UEA-1 and MAA were mainly found in the basal areas and arcade region rather than in 115 the secondary villi and examination of serial sections revealed that the cells that bound 116 UEA-1 more strongly were invariably those with no DBA or VVA staining; likewise 117 strongly stained DBA/VVA cells were generally negative with UEA-1 (Fig. 1F, G). Comparison of lectin binding of the same six cells with I-PHA, UEA-1, DBA and ECA can be seen (Fig. 1E-H).

121 In contrast to the staining of only small numbers of BNC with DBA and VVA, all the blood vessels were very strongly stained by these lectins, both in maternal and fetal tissues

123 (Fig. 1D), a feature uncommon in many ruminants but present in the giraffe and okapi 124 placenta. 
126 CONA, e-PHA, ALA, DSA, STA and SNA-1 bound to the BNC but they were hard to 127 distinguish from the uninucleate cells which also bound these lectins. PSA, LTA, MPA, 128 HPA, AHA and SBA (both lectins with and without neuraminidase) and MAA bound 129 weakly to moderately and with slight variations that were not very different from the 130 uninuclear cells. After neuraminidase, the background stain was slightly reduced with 131 SNA-1 making the BNC in the secondary villi more prominent.

BNC that had migrated into and fused with the maternal uterine epithelium were 134 particularly well shown by the fixation used. Migrated BNC (actually a BNC fused with a uterine cell, i.e. a trinucleate cell (TNC) or, in some cases, a syncytium containing several nuclei) showed polarisation of granules toward maternal vessels (Fig. 2A) into which, after migration (Fig. 2B) and granule exocytosis, the contents would diffuse. PAA, I-PHA, AHA after neuraminidase, MAA and WGA generally bound very strongly to TNC granules (Figs 2A, C, D). Figure $2 \mathrm{C}$ depicts a sequence of degranulation in TNC cells stained with MAA which shows the blood vessels particularly well.

One interesting feature was the amylase-resistant binding of BSA-II to selected cisternae (probably the cis face) of BNC Golgi bodies (Fig. 2E); AHA after neuraminidase bound to 144 a much wider proportion of saccules including trans cisternae (Fig. 2F). Other lectins 145 such as UEA-1, DBA and MAA, also showed occasional binding to Golgi cisternae, but 146 this was extremely variable and generally more diffuse.

148 Comparison of pronghorn BNC lectin staining with the results of giraffe and okapi BNC 149 (see Table 2) showed some similarities and some differences. DBA binding, absent in 
150 the giraffe and okapi, was also absent in the majority of the BNC in the pronghorn - only

$15130-40 \%$ of the BNC bound, and these were away from the basal regions of secondary

152 villi.

153

154 The strong staining of many BNC with LEA was also a feature of the giraffe, though not

155 okapi BNC, and was only weakly found in the bovine, while PAA bound strongly in

156 pronghorn, giraffe and okapi but not in the bovine. The levels of binding of I-PHA, UEA-1,

157 VVA and ECA were characteristic of the Pronghorn.

158

159 The selective staining of Golgi cisternae by BSA-Il was also present in giraffe though not

160 okapi, but this could have been due to poor fixation of the okapi tissue. Some staining

161 was evident in the bovine but it was also present elsewhere in some cells and was not

162 restricted to the Golgi of BNC.

163

164

165

\subsection{Immunocytochemistry of BNC}

Using Pregnancy Associated Glycoprotein antibodies Ovine PAG-1 and Bovine PAG-2,

166

(Fig. 3A-B), the pattern of BNC labelling in the pronghorn was very similar to that which we have previously demonstrated in Tragulids, Bovids and Cervids [3]. All showed a uniform distribution of positive BNC throughout the placentome, quite unlike the unique regional distribution seen in the Giraffids [7]. In contrast, neither the giraffe nor the pronghorn BNC labelled with SBU-3 (Fig. 3E), a monoclonal antibody which is strongly expressed in the BNC of the other three clades. Prolactin was only found in Giraffid $\mathrm{BNC}$ and it was restricted to the fetal end of the placentome, being negative in the pronghorn (Fig. 3D) and okapi. These results are summarised in Table 3. 


\section{Discussion}

177 The position of the pronghorn in relation to the Cervidae, Bovidae and Giraffidae has

178 been disputed for some time. The pronghorn is Bovid- and Giraffoid-like in that they both 179 have permanent bony horns and not annually grown and shed antlers like all Cervids. In 180 addition Bovids and Giraffids have over fifty placentomes per placenta, whereas Cervids 181 rarely have more than five or six; in pronghorn the number ranges from $46-180$, with an average of 92 [15]. However, most anatomical characters used to describe the pronghorn and its fossil relatives seem to place them close to the deer family (Cervidae) [16] and it does resemble an antelope in appearance [17]. Recent phylogenetic analysis, 185 however, indicates that the pronghorn family is most closely related to the Giraffidae, 186 forming a sister group to Cervidae and Bovidae, or a sister group to all other horned 187 ruminants $[8,16,18,19]$ rather than being classified in either Bovidae [2] or Cervidae 188 [20] although the placental type and permanent bony horns favour the Bovid 189 classification rather than the Cervids. DNA investigations indicate Antilocapridae is a 190 legitimate family of its own [21] and that its resemblance to the Bovid family of antelopes 191 of Africa and Eurasia is a feature of convergent evolution.

193 It was thus of interest to examine the placenta and glycosylation of the binucleate cells

194 of the pronghorn as those of the Giraffidae have been shown to have unique 195 characteristics when compared with other ruminants which have a highly conserved 196 pattern of glycosylation [5].

198 Our glycoprotein analysis has come up with some interesting features, indicating that 199 the pronghorn BNC has some features of the Giraffidae but also some of the Bovidae 200 and other ruminants as well as features of its own. Our detection of $\mathrm{H}$-type 2 antigen 
201 ( $\alpha$ L-Fuc $(1,2)$ Galß1,4- GlcNAcß1-) indicated by UEA-1 binding in sparse cells of the 202 basal areas of secondary villi appears to be unusual in ruminants, and in pronghorn was 203 generally associated with undetectable levels of GalNAc $\alpha 1,3$ (LFuc $\alpha 1,2)$-GalB1,3/4Glc204 NAcB1-) which is bound by DBA. Terminal a2,3-linked sialic acid-containing cells which 205 bound MAA were also to be occasionally found mainly in the basal and arcade regions, 206 and this was also found strongly in fused cells. The presence of this may be responsible 207 for the increased numbers of ECA-binding BNC observed after neuraminidase staining, 208 especially in basal areas of secondary villi and in the arcade region. Fucosylation was 209 also more prominent here in the BNC. The small size of the cells here, and their staining 210 characteristics that differ from other BNC, suggests that these cells may be immature. It 211 might also be that the absence of cells stained with DBA in the basal region of 212 secondary villi may be due to the fact that this area of trophoblast is similar to the 213 arcade region of intercotyledonary trophoblast, cells of which have a different function to 214 villous trophoblast. However, other BNC glycans appeared to be expressed in both 215 inter- and placentomal areas.

217 Tri/tetra-antennary, non-bisected N-glycan (I-PHA) was not as strongly expressed as in 218 most other ruminants, a feature found even more so in the okapi where it was almost 219 completely absent, and the strong expression of Galß1,4GICNAcß1- (ECA), with some 220 sub-terminal residues mainly in the basal secondary villi and arcades, was another 221 unique feature. Although non-bisected bi/tri-antennary,complex $\mathrm{N}$ - linked sequences 222 (PSA) found in pronghorn, giraffe and okapi were not present in the bovine, they have 223 been described in BNC of other ruminants [5]. 
225 The glycans expressed more in the BNC compared to uninucleate trophoblast cells appeared to be mainly $\mathrm{N}$-acetyl glucosamine oligomers as shown by the strong staining with LEA, PAA and WGA, plus terminal and subterminal N-acetyl lactosamine bound by

228 ECA before and after neuraminidase pretreatment. The fixation protocol used clearly 229 showed the polarisation and concentration of BNC granules once they had migrated 230 across to the maternal side and fused with uterine epithelium to form TNC or syncytia.

231 This was most clearly observed with I-PHA but careful examination with ECA, PAA, MAA and WGA staining revealed similar findings. This process ensured that the hormonal contents of the granules would thus pass into the maternal circulation as has been

234 previously demonstrated in the ovine and bovine $[4,12,22]$. An unusual observation was 235 the precise localisation of binding of BSA-II to selected (cis) cisternae of the Golgi apparatus, suggesting the site of post-translation modification of the secretory proteins with terminal $\alpha$ and $\beta \mathrm{N}$-acetyl glucosamine [23]. Other lectins bound to a more extensive network of Golgi cisternae, for instance, AHA after neuraminidase.

240 The immunocytochemical results clearly show that the pronghorn BNCs contain the two 241 PAG antigens which are found in BNCs throughout the placentome and the pattern of 242 labelling is very similar to that previously demonstrated in Tragulids, Bovids and Cervids $243[3,12]$. In contrast, only Bovine PAG2 is found in the giraffe, so in this respect the 244 pronghorn resembles the bovine more than giraffe. Interestingly, the okapi BNC also 245 expresses both PAG antigens but not bPI. There was no evidence for any placentomal 246 regional distribution of BNC content or prolactin antigen presence such as that reported in 247 the Giraffids [7]. However there is good evidence for the close relationship between 248 giraffes and pronghorns in the absence of any binding of the SBU-3 antibody to the BNC 249 granules in either. SBU-3 has been shown to recognise a tri/tetra antennary carbohydrate 
epitope [14] characteristic of the Bovids and Cervids and its absence indicates significant

251 differences in glycoprotein expression between the clades.

252

253 In summary, although the pronghorn outwardly resembles an antelope, and each clade

254 shows individual characteristics, there are far more similarities of the placentomes than

255 differences between them, emphasizing the common ancestry of all four clades. The

256 comparative data described here are, it should be noted, for phenotypes alone. These

257 may reflect ancestry and phylogeny, or may reflect independently evolved characteristics,

258 with giraffe and pronghorn having similar placental characters due to shared common

259 ancestry or each having evolved them separately.

260

261 Acknowledgement.

262 The authors would like to express their appreciation of the contribution of

263 Professor William Joseph Silvia (1956-2015) who unfortunately passed away

264 before finalisation of the paper. He was born in Providence, Rhode Island and

265 obtained his undergraduate degree in Animal Science at Cornell University

266 followed by an MSc in Reproductive Physiology (West Virginia University) and

267 PhD in Reproductive Endocrinology (Colorado State University). Dr Silvia was a

268 passionate and untiring scholar of science, an eternal student of the world,

269 naturalist, travel-explorer, a gifted teacher, a loving son and a devoted husband

270 and father and is greatly missed by his colleagues.

271

$272 \quad$ Funding

273 This research did not receive any specific grant from funding agencies in the

274 public, commercial, or not-for-profit sectors. 


\section{References:}

276

277 [1] E. Davis, Family Antilocapridae, in: D. Prothero, S. Foss (Eds.), The Evolution 278 of the Artiodactyls, Johns Hopkins University Press, Baltimore, 2007, pp. 227-240. 279

280 [2] B.W. O'Gara, G. Matson, Growth and casting of horns by pronghorn and 281 exfoliation of horns by bovids. J. Mammal. 56 (1975) 829-846.

282

283 [3] P. Wooding, G. Burton, Comparative Placentation - Structures, Functions and 284 Evolution. Springer-Verlag, Berlin, Heidelberg, 2008.

285

286

[4] F.B. Wooding, G. Morgan, I.A. Forsyth, G. ButcheR, A. Hutchings, S.A.

287 Billingsley, P.D. Gluckman, 1992. Light and electron microscopic studies of cellular 288 localization of oPL with monoclonal and polyclonal antibodies. J. Histochem. 289 Cytochem. 40 (1992) 1001-1009.

290

291 [5] K. Klisch, F.B.P. Wooding, C.J.P. Jones, The glycosylation pattern of secretory 292 granules in binucleate trophoblast cells is highly conserved in ruminants.

293 Placenta 31 (2010) 11-17.

294

295 [6] C.J. Jones, S.A. Wilsher, F.B. Wooding, K. Benirschke, W.R. Allen, The 296 binucleate cell of okapi and giraffe placenta shows distinctive glycosylation 297 compared with other ruminants: a lectin histochemical study. Mol. Phylogenet. Evol. $29883(2015) 184-190$.

299 
[7] F.B.P. Wooding, S. Wilsher, K. Benirschke, C.J.P. Jones, W.R. Allen,

301 Immunocytochemistry of the placentas of giraffe (Giraffa cameleopardalis giraffa)

302 and okapi (Okapi johnstoni): Comparison with other ruminants. Placenta 36 (2015)

$303 \quad 77-87$.

304

305 [8] R.W. Meredith, J.E. Janečka, J. Gatesy, O.A. Ryder, C.A. Fisher, E.C. Teeling,

306 A. Goodbla, E. Eizirik, T.L.L. Simão, T. Stadler, D.L. Rabosky, R.L. Honeycutt, J.J.

307 Flynn, C.M. Ingram, C. Steiner, T.L. Williams, T.J. Robinson, A. Burk-Herrick, N.M.

308 Westerman, A. Ayoub, M.S. Springer, W.J. Murphy, Impacts of the Cretaceous

309 Terrestrial Revolution and KPg Extinction on Mammal Diversification. Science 334

310 (2011) 521-524.

311

312 [9] C.J. Jones, A.M. Carter, J.D. Aplin, A.C. Enders, Glycosylation at the

313 fetomaternal interface in hemomonochorial placentae from five widely separated

314 species of mammal: is there evidence for convergent evolution? Cells Tiss. Org.

$315185(2007) 269-284$.

316

317 [10] C.J.P. Jones, C.A. Morrison, R.A. Stoddart, Histochemical analysis of rat

318 testicular glycoconjugates. 1) Subsets of $\mathrm{N}$-linked saccharides in seminiferous

319 tubules. Histochem. J. 24 (1992) 319-326.

320

321 [11] C.J. Jones, S.C. Whittle, J.D. Aplin, A simple histochemical method for the

322 identification of cytotrophoblasts in tissue sections. Placenta 42 (2016) 84-86. 
324 [12] F.B. Wooding, R.M. Roberts, J.A. Green, Light and electron microscope

325 immunocytochemical studies of the distribution of pregnancy associated

326 glycoproteins (PAGs) throughout pregnancy in the cow: possible functional

327 implications. Placenta 26 (2005) 807-827.

328

329 [13] C.S. Lee, F.B.P. Wooding, M.R. Brandon, M. R, Immunogold co-localization of

330 ovine placental lactogen and the antigen recognized by the SBU-3 monoclonal

331 antibody in sheep placental granules. J. Reprod. Fertil. 78 (1986) 653-662.

332

333 [14] Y.H. Atkinson, K.J. Gogolin-Ewens, E.F. Hounsell, M.J. Davies, M.R.

334 Brandon, R.F. Seamark, Characterization of placentation-specific binucleate cell

335 glycoproteins possessing a novel carbohydrate. Evidence for a new family of

336 pregnancy-associated molecules. J. Biol. Chem. 268 (1993) 26679-26685.

337

338 [15] B.W. O'Gara, Unique aspects of reproduction in the female pronghorn

339 (Antilocapra americana Ord). Amer. J. Anat. 125 (1969) 217-232.

340

341 [16] C.M. Janis, Ruminants of the Neogene of North America, in: E. Vrba, G.

342 Schaller (Eds.), Antelopes, Deer, and Relatives: Fossil Record, Behavioral Ecology,

343 Systematics, and Conservation. Yale University Press, New Haven and London, 3442000, pp. 26-37.

345

346 [17] J.D. Caton, The American Antelope, or Prong Buck. Am. Nat. 10 (1876) 193347205. 
349 [18] M. Hernández Fernández, E.S. Vrba, A complete estimate of the phylogenetic

350 relationships in Ruminantia: a date species-level supertree of extant ruminants.

351 Biol. Rev. 80 (2005) 269-302.

352

353 [19] L. Murray, The smaller Artiodactyls: peccaries, oxen, deer, and pronghorns, in:

354 G. Jefferson, L. Lindsay (Eds), Fossil Treasures of the Anza-Borrego Desert: the

355 Last Seven Million Years. Sunbelt Publications, San Diego, California, 2006, $356 \quad$ pp.273-287.

357

358 [20] C.M. Janis, K.M. Scott, The interrelationships of higher ruminant families with 359 special emphasis on the members of the Cervoidea. Am. Mus. Novit. 983 (1987) 136085.

361

362 [21] M.A. Cronin, R. Stuart, B.J. Pierson, J.C. Patton, Kappa-casein gene 363 phylogeny of higher ruminants (Pecora, Artiodactyla). Mol. Phylogenet. Evol. 6 364 (1996) 295-311.

365

366 [22] F.B. Wooding, J.F. Beckers, Trinucleate cells and the ultrastructural

367 localisation of bovine placental lactogen. Cell Tiss. Res. 247 (1987) 667-673.

368

369 [23] S. Ebisu, P.N. Shankar lyer, I.J. Goldstein, Equilibrium dialysis and

370 carbohydrate-binding studies on the 2-acetamido-2-deoxy-D-glucopyranosyl-

371 binding lectin from Bandeiraea simplicifolia seeds. Carbohydrate Res. 61 (1978)

$372 \quad 129-138$.

373 


\section{$374 \quad$ Figure legends}

375 Figure 1: Toluidine blue and lectin staining to show general structure of 376 Pronghorn placentomes.

377 A) The fetal end showing the arcade region and basal ends of secondary villi which 378 interdigitate with those from the maternal villus (Mat villus) running along the centre 379 of the image. The stroma of the maternal villus is always denser than that of the 380 fetal villus. Scale bar: $200 \mu \mathrm{m}$

381 B) The maternal end of the placentome with processes forming villi running 382 between and interdigitating with the thicker fetal villi. Scale bar: $200 \mu \mathrm{m}$

383 C) Section stained with LEA showing numerous binucleate cells (BNC) in the fetal 384 villi, including the curved basal ends. Uninucleate cells do not stain. The maternal 385 epithelial cells strongly bind this lectin. BNC: binucleate cells. Scale bar: $100 \mu \mathrm{m}$ 386 D) With DBA, only a subpopulation of BNC bind the lectin, and none are present in 387 the basal ends. Both fetal (FBV) and maternal blood vessels (MBV) also bind DBA. 388 BNC: binucleate cells. Scale bar: $100 \mu \mathrm{m}$

389 E-H) Serial sections stained with I-PHA, UEA-1, DBA and ECA showing numbered 390 cells bind the lectins to different degrees. Those strongly binding DBA are not 391 stained with UEA-1, which tend to be mainly in the basal ends of the villi; I-PHA and 392 ECA tend to bind most, but not all, BNC.

393 MV: maternal villus, FV: fetal villus, BV: blood vessel, BE: basal end of the villus.

394 Scale bars: $50 \mu \mathrm{m}$

\section{Figure 2 Features of binucleate cell glycosylation}

396 A) BNC stained with I-PHA that have fused with maternal epithelium (arrows) show 397 polarisation of their granules toward maternal blood vessels in the stroma of the 398 villi. Scale bar: $50 \mu \mathrm{m}$ 
B) A BNC stained with MAA (arrow) in the process of migrating out of the

400 trophoblast layer towards a maternal villus which is poorly preserved in this region.

401 Scale bar: $25 \mu \mathrm{m}$

402 C) Various TNC stained with MAA in different stages of progressive (1-4)

403 degranulation into maternal blood stromal compartment. Scale bar: $25 \mu \mathrm{m}$

404 D) PAA lectin binds to fused tri/multinucleate cells of the maternal uterine

405 epithelium. Scale bar: $50 \mu \mathrm{m}$

406 E) BSA-Il binds strongly to selected Golgi cisternae of BNC. Scale bar: $25 \mu \mathrm{m}$

407 F) AHA after neuraminidase binds strongly to a wide area of Golgi cisternae in

408 BNC. Scale bar: $25 \mu \mathrm{m}$

409 MV: maternal villus $\mathrm{FV}$ : fetal villus

410 Figure 3 Immunocytochemistry of BNC in Pronghorn.

411 A-B) Pregnancy associated glycoprotein antibodies Ovine PAG-1 and Bovine PAG-

4122 bind to Pronghorn BNC. MV: maternal villus, FV: fetal villus

413 C) SBU-3 antigen is not expressed in Pronghorn BNC.

414 D) Bovine Prolactin antibody does not bind to Pronghorn BNC. Scale bars A-D:

$415100 \mu \mathrm{m}$

416 
Table1: Pronghorn twin fetal characteristics.

\begin{tabular}{ccc}
\hline $\begin{array}{l}\text { Specimen } \\
\text { number }\end{array}$ & $\begin{array}{l}\text { Crown-Rump } \\
\text { Lengths }(\mathrm{mm})\end{array}$ & Average weight (g) \\
\hline 1 & $307 / 301$ & 1134 \\
2 & $290 / 290$ & 1025 \\
3 & $288 / 290$ & 1080 \\
4 & $284 / 290$ & 995 \\
5 & $283 / 277$ & 900 \\
6 & $318 / 295$ & 1000
\end{tabular}


Click here to download Table: Final Table 2 Pronghorn.docx

Table 2: Lectin binding to BNC in Two Pronghorn, Giraffe, Okapi and Bovine placentae

\begin{tabular}{|c|c|c|c|c|c|c|c|}
\hline Lectin & Source & Major specificity & $\begin{array}{l}\text { Prong- } \\
\text { horn } 1\end{array}$ & $\begin{array}{l}\text { Prong- } \\
\text { horn } 6\end{array}$ & $\begin{array}{l}\text { Giraffe } \\
\text { cot'n }\end{array}$ & $\begin{array}{l}\text { Okapi } \\
\text { cot'n }\end{array}$ & $\begin{array}{l}\text { Bovine } \\
\text { cot'n }\end{array}$ \\
\hline CONA & Canavalia ensiformis & & $3(4+)$ & $3(4+)$ & $3(4+/-)$ & $3-4$ & 3 \\
\hline PSA & Pisum sativum & $\begin{array}{l}\text { residues in nign mannose, } \\
\text { small, bi- tri- or tetra- }\end{array}$ & 2 & 2 & 3 & 2 & $1(4+/-)$ \\
\hline e-PHA & $\begin{array}{l}\text { Phaseolus vulgaris - } \\
\text { erythroagglutinin }\end{array}$ & $\begin{array}{l}\text { antennary, bisected or non } \\
\text { bisected complex } \mathrm{N} \text { - linked } \\
\text { sequences }\end{array}$ & 3 & 3 & 3 & $3-4$ & $3-4$ \\
\hline I-PHA & $\begin{array}{l}\text { Phaseolus vulgaris - } \\
\text { leucoagglutinin }\end{array}$ & & $\begin{array}{l}2-3 \\
(4+)\end{array}$ & $\begin{array}{l}2-3 \\
(4+)\end{array}$ & 4 & 1 & 4 \\
\hline LTA & Lotus tetragonolobus & L-Fucose terminals linked to & 1 & 1 & $1-2$ & 1 & 0 \\
\hline UEA-1 & Ulex europaeus-1 & glucosamine & $1-3$ & $1-2$ & 0 & 1 & 0 \\
\hline ALA & Aleuria aurantia & & 4 & 4 & 4 & $3-4$ & 4 \\
\hline MPA & Maclura pomifera & Galactose/aN-acetyl & 3 & $2-3$ & $2-3(4+/-)$ & $3-4$ & $1 / 2++$ \\
\hline $\mathrm{BSA}-1 \mathrm{~B}_{4}$ & Bandeirea simplicifolia- $1_{4}$ & & $1-2$ & $1-2$ & $3-4$ & 2 & $0-1$ \\
\hline $\mathrm{AHA}$ & Arachis hypogaea & Terminal $\beta$ Galactose & $1-2$ & $1-2$ & $1-2(4+/-)$ & $2-3$ & 1 \\
\hline $\mathrm{AHA}+\mathrm{N}$ & $\begin{array}{l}\text { Arachis hypogaea after } \\
\text { neuraminidase }\end{array}$ & Subterminal $\beta$ Galactose & $\begin{array}{l}1-2 \\
\text { Golgi } 4\end{array}$ & $\begin{array}{l}2 \\
\text { Golgi } 4\end{array}$ & $2-3$ & $2-3$ & $2-3$ \\
\hline ECA & Erythrina cristagalli & $\begin{array}{l}\text { Terminal } \mathrm{N} \text { - } \\
\text { acetyllactosamine }\end{array}$ & $1-3 / 4$ & $1-3 / 4$ & $2(4+/-)$ & 2 & 1 \\
\hline $\mathrm{ECA}+\mathrm{N}$ & $\begin{array}{l}\text { Erythrina cristagalli } \\
\text { after neuraminidase }\end{array}$ & $\begin{array}{l}\text { Subterminal N- } \\
\text { acetyllactosamine }\end{array}$ & 4 & 4 & 3 & 4 & $2-3$ \\
\hline DBA & Dolichos biflorus & aN-acetylgalactosamine & $1-4$ & $1-4$ & 0 & 0 & 4 \\
\hline VVA & Vicia villosa & & $1-4$ & $1-4$ & $1(4+/-)$ & 1 & 2 \\
\hline HPA & Helix pomatia & & $2-3$ & $2-3$ & $2-3$ & $1-2$ & $1(3+/-)$ \\
\hline WFA & Wisteria floribunda & & $2-4$ & $2-3 / 4$ & 3 & $2-3$ & $3-4$ \\
\hline SBA & Glycine max & & $1-2$ & $1-2$ & $2-3$ & 2 & $1(2+/-)$ \\
\hline $\mathrm{SBA}+\mathrm{N}$ & $\begin{array}{l}\text { Glycine max after } \\
\text { neuraminidase }\end{array}$ & $\begin{array}{l}\text { Subterminal } \alpha \mathrm{N}- \\
\text { acetylgalactosamine }\end{array}$ & 2 & 2 & 3 & 2 & 3 \\
\hline BSA-II & Bandeirea simplicifolia-II & $\begin{array}{l}\text { Terminal } \alpha \text { and BNAcetyl } \\
\text { glucosamine }\end{array}$ & $\begin{array}{l}1 \\
\text { Golgi } 4\end{array}$ & $\begin{array}{l}1 \\
\text { Golgi } 4\end{array}$ & $\begin{array}{l}1 \\
\text { Golgi } 4\end{array}$ & $1-2$ & $\begin{array}{l}1 \\
\text { Golgi 2-3 }\end{array}$ \\
\hline$\overline{D S A}$ & Datura stramonium & $\begin{array}{l}\mathrm{N} \text {-acetyl-glucosamine } \\
\text { oligomers and/ or N-acetyl } \\
\text { lactosamine }\end{array}$ & $3-4$ & $3-4$ & 4 & $3-4$ & 4 \\
\hline STA & Solanum tuberosum & & $3-4$ & $3-4$ & 3 & 3 & $2-3$ \\
\hline LEA & Lycopersicon esculentum & & $3-4$ & $3-4$ & 4 & 1 & $1-2$ \\
\hline PAA & Phyttolacca americana & & $2-3^{*}$ & $2-3^{*}$ & $3-4$ & $3-4$ & $1(3+/-)$ \\
\hline $\mathrm{PAA}+\mathrm{N}$ & $\begin{array}{l}\text { Phyttolacca americana } \\
\text { after neuraminidase }\end{array}$ & $\begin{array}{l}\text { Terminal/subterminal N- } \\
\text { acetyl-glucosamine } \\
\text { oligomers and/ or } \mathrm{N} \text {-acetyl } \\
\text { lactosamine. }\end{array}$ & $3^{*}$ & $3^{*}$ & $3-4$ & $3-4$ & $1-2(3+/-)$ \\
\hline WGA & Triticum vulgaris & $\begin{array}{l}\mathrm{N} \text {-acetyllactosamine, di-N- } \\
\text { acetyl chitobiose, sialic acid }\end{array}$ & $1-3^{*}$ & $1-3^{*}$ & $3-4$ & $3-4$ & $3-4$ \\
\hline $\mathrm{WGA}+\mathrm{N}$ & $\begin{array}{l}\text { Triticum vulgaris after } \\
\text { neuraminidase }\end{array}$ & $\begin{array}{l}\mathrm{N} \text {-acetyllactosamine, di-N- } \\
\text { acetyl chitobiose, }\end{array}$ & $1-3^{*}$ & $1-3^{*}$ & $3-4$ & $3-4$ & $1-2(3+/-)$ \\
\hline SNA-1 & Sambucus nigra & $\begin{array}{l}\text { Terminal } \alpha 2,6 \text {-linked sialic } \\
\text { acid/N-acetyl galactosamine }\end{array}$ & $3-4$ & 3 & $3-4$ & $3-4$ & $1-2$ \\
\hline SNA-1+N & $\begin{array}{l}\text { Sambucus nigra after } \\
\text { neuraminidase }\end{array}$ & $\mathrm{N}$-acetyl galactosamine & $3-4$ & 3 & 2 & $3-4$ & 2 \\
\hline MAA & Maackia amurensis & $\begin{array}{l}\text { Terminal } \alpha 2,3 \text {-linked sialic } \\
\text { acid }\end{array}$ & 2 & $1-0 c c 3$ & $2-3$ & $1-2$ & 4 \\
\hline $\mathrm{MAA}+\mathrm{N}$ & $\begin{array}{l}\text { Maackia amurensis after } \\
\text { neuraminidase }\end{array}$ & & 0 & 0 & 1 & 1 & $1-2$ \\
\hline
\end{tabular}

Key: 0: negative, 1: weak, 2: moderate, 3: strong, 4: intense lectin binding. Bracket: presence of sparse dark granules in cells. cot'n: cotyledon. * $: 4$ when merged with maternal epithelium. $+\mathrm{N}$ : after neuraminidase 
Click here to download Table: Revised Table 3.docx

Table 3: Immunocytochemistry of BNC

\begin{tabular}{lcclc}
\hline Antibody & Bovine & Pronghorn & Giraffe & Okapi \\
\hline Ovine PAG-1 & + & + & - & + \\
Bovine PAG-2 & + & + & $+^{*}$ & + \\
bPL & + & - & $+^{*}$ & - \\
SBU-3 & + & - & - & - \\
PRL & - & - & + & -
\end{tabular}

*Fetal end only 
Figurs

cilet
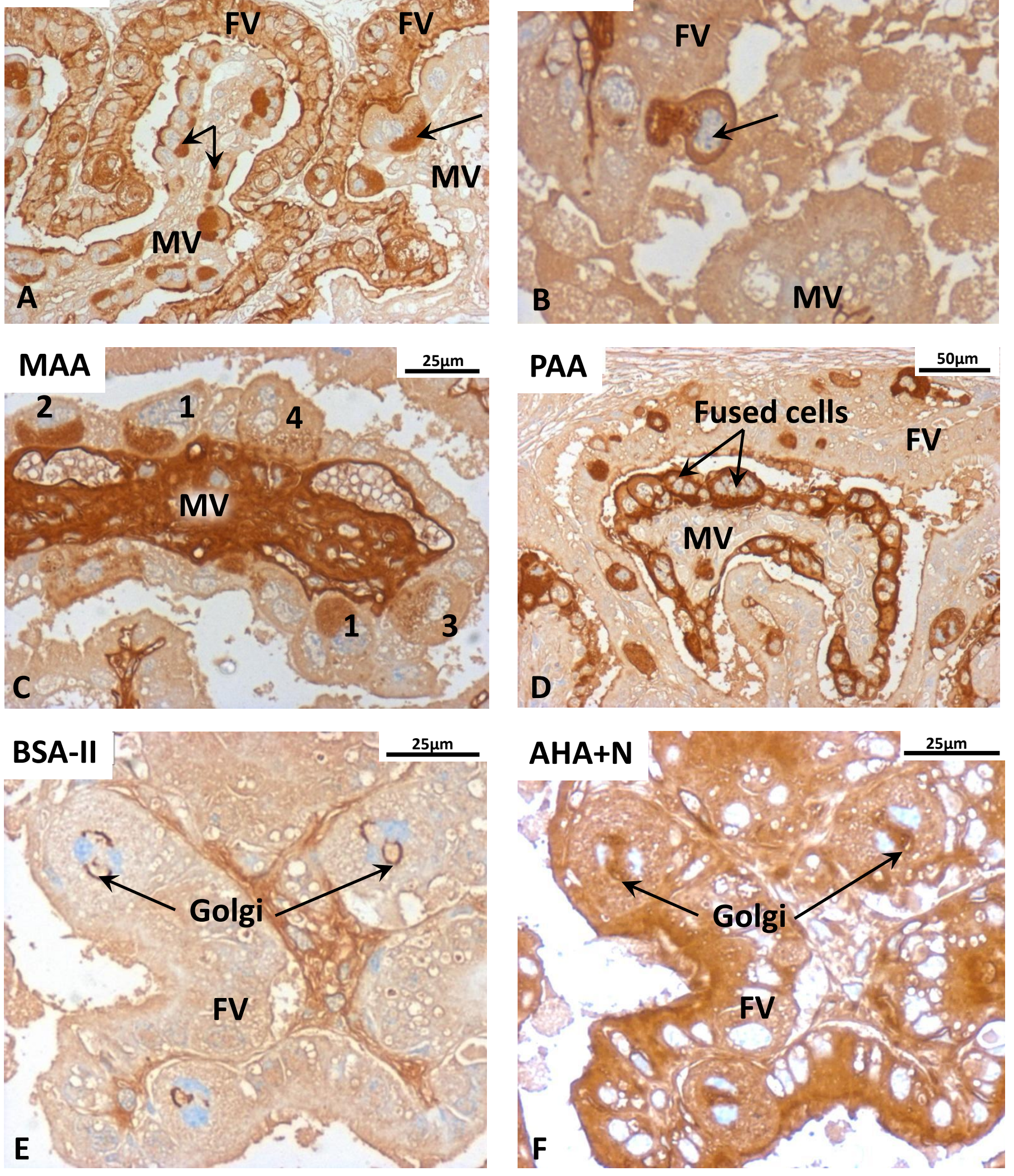
Figure

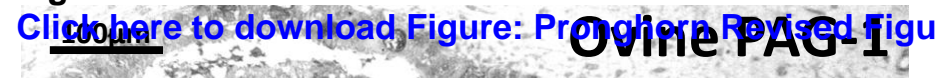
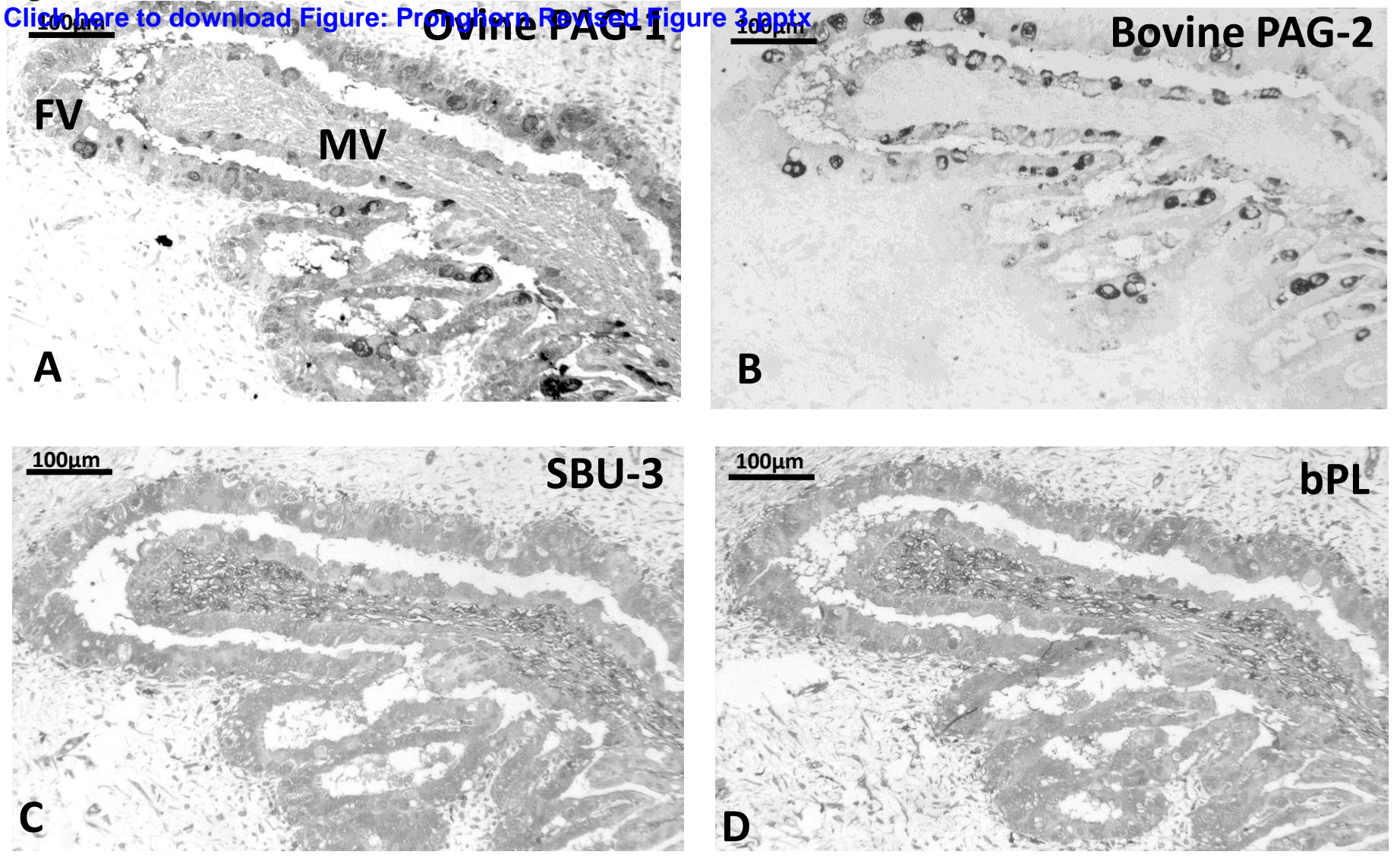